\title{
A Preferência Visual Percebida em Tênis de Corrida
}

\section{Perceived Visual Preference in Running Shoes}

\author{
SILVA, Renan Cruz da; \\ Universidade Federal de Pernambuco | Mestre em Design \\ renan.cruz01@gmail.com
}

COSTA FILHO, Lourival

Universidade Federal de Pernambuco | Doutor em Desenvolvimento Urbano

lourivalcosta@yahoo.com

\begin{abstract}
RESUMO
O presente artigo tem como objetivo avaliar a preferência do público esportista por tênis de corrida com diferentes qualidades estéticas. Para tal, tomou-se duas características de seus elementos estéticos, complexidade e coerência, para estudo, por suas possíveis influências na qualidade visual percebida. A investigação empírica foi desenhada a partir de uma sentença estruturadora - instrumento básico da Teoria das Facetas - e utilizou como procedimentos metodológicos um questionário online, por meio da ferramenta Google Formulários, para coletar os dados e tabelas de frequências para interpretá-los. Os resultados apontaram que a preferência pelo objeto estudado é elevada pela complexidade alta e pela coerência baixa (contraste alto) de seus elementos, tanto para o público feminino quanto para o masculino.
\end{abstract}

tênis de corrida, qualidade visual percebida, design do produto, ergonomia do produto.

\section{ABSTRACT}

This article aims to evaluate the preference of the sportsman public for running shoes with different aesthetic qualities. For this, two aesthetic characteristics of running shoes, complexity and coherence, were taken for study, because of their likely influence on perceived visual quality. Empirical investigation was designed from a mapping sentence - basic tool of the Facet Theory - which used as methodological procedures an online questionnaire, through the Google Forms tool, to collect data and tables of frequencies to interpret them. The results showed that the preference for studied object is high due to the high complexity and low coherence (high contrast) of its elements, for both female and male audiences.

running shoes, perceived visual quality, product design, ergonomics of product.

\section{INTRODUÇÃO}

Um considerável número de pessoas da sociedade brasileira vem aderindo a uma nova prática que, entre outros motivos, tem por objetivo principal a melhoria da qualidade de vida: 0 


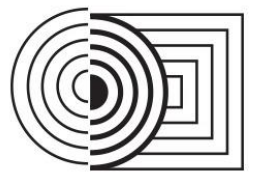

\section{$17^{\circ}$ ERGODESIGN \& USIHC 2019 \\ PUC-Rio, 11 a 13 de dezembro \\ Rio de Janeiro, RJ, Brasil}

$17^{\circ}$ Ergodesign - Congresso Internacional de Ergonomia e Usabilidade de Interfaces Humano Tecnológica: Produto, Informações Ambientes Construídos e Transporte

$17^{\circ}$ USIHC - Congresso Internacional de Ergonomia e Usabilidade de Interfaces Humano Computador

movimento fitness. Com os adeptos de academias e de atividades de rua - ciclismo e corrida -, ou mesmo aqueles que preferem as últimas tendências do segmento, como os exercícios funcionais ou crossfit, um novo nicho de mercado de consumidores vem se consolidando nos últimos anos.

Em uma matéria para o jornal O Globo, LEAL at al (2015) destaca as corridas de rua como uma pandemia global. A massificação é considerada evidente, e é justificada por fatores como: a melhoria da performance no esporte; questões relacionadas à saúde e ao bem-estar; e a socialização entre os praticantes. O Cognatis (2018), ao se referir a popularização das academias, adiciona a busca por um ideal de beleza como mais um motivo que justifica a aderência de cerca de 8 milhões de brasileiros a essa atividade.

Tal fenômeno chama a atenção de grandes companhias de diversos segmentos, que ao enxergarem a oportunidade, procuram se adequar a esse mercado. No que diz respeito à tecnologia assistiva (smartphones, smartwatches, wristbands, entre outros), o Brasil já se encontra em terceiro na lista de maiores países consumidores (GFK, 2016). Em relação a outros tipos de produtos - como os calçados -, a promoção de experiências e o design centrado no usuário têm sido utilizados como estratégias para garantir um bom desempenho no mercado. (CAVALCANTI, 2016).

Dado o impacto que o mercado de consumo por produtos do segmento fitness tem nos dias de hoje, o presente estudo objetiva avaliar a preferência do público esportista por tênis de corrida. A partir da análise da preferência dos usuários - participantes desta pesquisa - por modelos de calçados com diferentes qualidades estéticas, espera-se prover dados norteadores sobre a qualidade visual percebida nesses produtos, para o auxílio no desenvolvimento de futuros projetos de calçados esportivos.

\section{CONSIDERAÇÕES TEÓRICAS}

A Qualidade Visual Percebida foi escolhida como objeto de estudo teórico para a presente pesquisa. De acordo com Nasar (2000), conceitua-se como Qualidade Visual Percebida a construção psicológica que envolve avaliações subjetivas, apoiadas em julgamentos perceptuais/cognitivos (referentes às características estéticas de um entorno) e julgamentos emocionais (referentes aos sentimentos das pessoas para essas características). Considera-se, no entanto, que embora a Qualidade Visual Percebida seja um processo perceptual/cognitivo, por definição, é um julgamento emocional que envolve avaliação e sentimento.

Para Russel (1988), existem quatro dimensões básicas das quais as respostas avaliativas afetivas de uma pessoa sobre algo se encaixam: agradabilidade, estímulo, excitação e relaxamento ${ }^{1}$. A agradabilidade pode ser descrita como uma dimensão puramente avaliativa. $O$ estímulo, por sua vez, independe dessa dimensão. Já a excitação e o relaxamento são resultantes de misturas de avaliação e estímulo. Para que tais avaliações ocorram, considerase não apenas o entorno estético que está sendo avaliado, mas todo o contexto do qual o avaliador se encontra, incluindo suas experiências estéticas prévias. Além disso, é necessário levar em conta os componentes notáveis preditores da preferência presentes nesse entorno. Para Kaplan (1988), todo indivíduo possui dois aspectos instintivos para a sobrevivência: o "envolvimento" e o "fazer sentido"2. Enquanto o primeiro relaciona-se com aquilo que provoca ou estimula um indivíduo; o segundo promove a compreensão. Assim, uma vez que ambos os

\footnotetext{
${ }^{1}$ Tradução livre de pleasant, arousing, exciting, relaxing.

2 Tradução livre de involvement e making sense.
} 


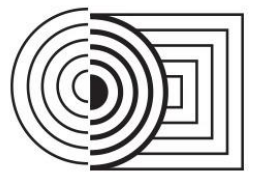

\section{$17^{\circ}$ ERGODESIGN \& USIHC 2019 \\ PUC-Rio, 11 a 13 de dezembro \\ Rio de Janeiro, RJ, Brasil}

$17^{\circ}$ Ergodesign - Congresso Internacional de Ergonomia e Usabilidade de Interfaces Humano Tecnológica: Produto, Informações Ambientes Construídos e Transporte

$17^{\circ}$ USIHC - Congresso Internacional de Ergonomia e Usabilidade de Interfaces Humano Computador

aspectos tendem a coexistir em um entorno estético, eles também se relacionam com dois componentes notáveis preditores da preferência: a complexidade e a coerência.

De acordo com Kaplan (1988), a complexidade se refere à diversidade de elementos presentes em um determinado entorno estético. Já a coerência, por sua vez, refere-se aos fatores que fazem com que um entorno estético seja fácil de compreender. Isto inclui elementos como as cores, texturas e formas presentes nele. Para o presente estudo, considera-se que a coerência será relacionada com o contraste entre cores presentes no entorno estético dos produtos selecionados.

Para Berlyne (1972), a preferência pela complexidade é elevada quando ela é utilizada de forma moderada em um entorno estético. Para o autor, um nível baixo gera monotonia e cansaço, enquanto o nível elevado provoca caos e estresse no observador. O nível moderado, portanto, é o ideal para o envolvimento. A coerência, por sua vez, tem a preferência elevada quando é apresentada em excesso (KAPLAN, 1988, NASAR, 2000). Para esta pesquisa, o excesso de coerência será representado pela redução do contraste entre os elementos presentes no entorno estético dos produtos.

De acordo com Nasar (2000), esses julgamentos são considerados favoráveis para um entorno estético quando um número significativo de pessoas comuns que o experienciam regularmente - ao invés de um especialista em projetos - assim acharem. Nesse sentido, o presente estudo apresentará os julgamentos avaliativos de diferentes adeptos de modalidades esportivas para diversos tênis de corrida, a fim de atingir os objetivos pretendidos.

\section{CONSIDERAÇÕES TEÓRICO - METODOLÓGICAS}

Para o desenvolvimento do presente estudo, optou-se pelo uso de uma Sentença Estruturadora, a fim de conciliar a pesquisa teórica com o levantamento empírico de dados (desenho da investigação empírica). Esta, por sua vez, apresenta-se como uma ferramenta da Teoria das Facetas. Elaborada e desenvolvida por Guttman, durante a década de 1950, essa metateoria é descrita por Bilsky (2003) como um procedimento metodológico que facilita expressar suposições teóricas, isto é, hipóteses, de tal forma que se pode examinar empiricamente a sua validade.

As Facetas referem-se ao universo das variáveis da pesquisa. Estas podem ser divididas em três tipos distintos: a Faceta da população dos indivíduos considerados na pesquisa; a Faceta do conteúdo das variáveis pesquisadas, isto é, os estímulos, itens, perguntas, entre outros. Considera-se que a Faceta de conteúdo e a Faceta da população formam, juntas, o campo de interesse da pesquisa, também chamado de domínio; e, por fim, a Faceta do racional, que se refere às possíveis respostas dos indivíduos (BILSKY, op. cit.).

A Sentença Estruturadora é uma ferramenta que apresenta de forma resumida todo o delineamento da pesquisa, utilizando essas Facetas. Sua leitura é feita da esquerda para direita, em que os elementos de cada Faceta são aplicados de forma aditiva, resultando assim em sentenças que expressam relações mútuas e que podem ser tomadas como hipóteses. Com esse processo, um universo de situações que requerem explicações é determinado inequivocamente pelas Facetas e suas inter-relações, dentro do campo de interesse da pesquisa (BILSKY, op. cit.).

A Sentença Estruturadora, como uma referência inicial da pesquisa, será analisada em relação aos resultados empíricos que devem contestar ou corroborar essa estrutura. Dessa forma, após a interpretação dos dados e na fase final, promove informações para construir ou não uma nova sentença como consequência direta dos resultados empíricos. (COSTA FILHO, 2014). 


\section{CONSIDERAÇÕES METODOLÓGICAS}

Na construção da Sentença Estruturadora para a avaliação da preferência do público esportista por tênis de corrida, com diferentes qualidades estéticas (Quadro 1), a faceta de população corresponde ao grupo de indivíduos abordados nesta pesquisa, ou seja, atletas do sexo masculino e feminino. Com essa divisão entre os gêneros, é pretendido que seja realizada uma comparação dos resultados. No tipo de faceta de conteúdo, que fora aqui dividida em duas, estão representadas as variáveis de complexidade e coerência com seus elementos internos, correspondentes a uma escala de variação. A faceta de racional, por fim, apresenta as possibilidades de respostas dos participantes, que são comuns a todas as facetas.

Quadro 1 - Sentença estruturadora para a avaliação da preferência do público esportista por tênis de corrida

Em que extensão a pessoa $(\mathrm{x})$ avalia que os efeitos das características estéticas de

FACETA A: CONTRASTE

(A1) contraste baixo

(A2) contraste médio

(A3) contraste alto

\section{FACETA B: COMPLEXIDADE}

(B1) complexidade mínima

(B2) complexidade moderada

(B3) complexidade máxima

\section{RACIONAL}

(1) nada

(2) pouco

(3) mais ou menos

o prazer de ter ou usar um tênis de corrida.

(4) muito

(5) demais

Fonte: Os autores da pesquisa (2018).

A sentença estruturadora atua como uma estrutura geral que liga todas as facetas (população, conteúdo, racional) e resulta em uma frase que norteia o projeto do instrumento de coleta de dados. Essa estrutura reflete a hipótese geral sobre as relações entre os elementos internos das facetas, sendo precisamente essas relações que serão testadas na situação empírica. A partir dessa sentença estruturadora, os elementos das facetas de conteúdo (contraste, complexidade) podem ser organizados de forma semelhante a uma análise matemática de combinação, produzindo ao todo 9 diferentes conjuntos ( $A 3 \times B 3=A B 9)$, que transmitem uma relação ou situação específica. A seta indica o mapeamento do conteúdo no conjunto de possibilidades de respostas, ou seja, cada um desses estruturantes compartilha de um racional comum, que apresenta a variedade de cinco respostas possíveis.

A geração desses conjuntos, diretamente associada às variáveis desta pesquisa, listadas na sentença estruturadora, aprimorou a escolha de 9 modelos de tênis para corrida com diferentes qualidades estéticas (Figura 1) - coletados em diversos websites da Internet e, dependendo da situação, tratados para se adaptarem à proposta da pesquisa - foram apresentados em um questionário online, por meio da ferramenta Google Formulários, apoiando a coleta dos dados. 
$17^{\circ}$ ERGODESIGN \& USIHC 2019

PUC-Rio, 11 a 13 de dezembro

Rio de Janeiro, RJ, Brasil $17^{\circ}$ Ergodesign - Congresso Internacional de Ergonomia e Usabilidade de Interfaces Humano Tecnológica: Produto, Informações Ambientes Construídos e Transporte

$17^{\circ}$ USIHC - Congresso Internacional de Ergonomia e Usabilidade de Interfaces Humano Computador

Figura 1: Nove elementos de estímulo representando as relações de contraste e complexidade.

\begin{tabular}{cc}
\hline \multicolumn{2}{c}{ LEGENDA } \\
\hline CONTRASTE $(\mathrm{A})$ & COMPLEXIDADE (B) \\
\hline A1 Contraste Baixo & B1 Complexidade Mínima \\
A2 Contraste Médio & B2 Complexidade Moderada \\
A3 Contraste Alto & B3 Complexidade Máxima \\
\hline
\end{tabular}

\begin{tabular}{|l|l|l|}
\hline & & \\
\hline
\end{tabular}

Fonte: Os autores da pesquisa (2018). 
Além das imagens, o questionário online utilizado nessa pesquisa contou com um modelo de respostas em escala Likert, baseada na faceta de racional da Sentença Estruturadora para a avaliação da preferência do público esportista por tênis de corrida.

Inicialmente, após responderem às informações iniciais para posterior definição do perfil da amostra, os participantes eram introduzidos ao questionário com a seguinte instrução:

"Observando os modelos de tênis de corrida apresentados abaixo, classifique-os quanto ao prazer de ter ou usá-los".

Em seguida, os respondentes poderiam escolher uma opção que ia do número um - referente à opção "nada" - ao número cinco - que se referia a opção "demais" (Figura 2).

Figura 2 - Exemplo do modelo de avaliação presente no questionário online.

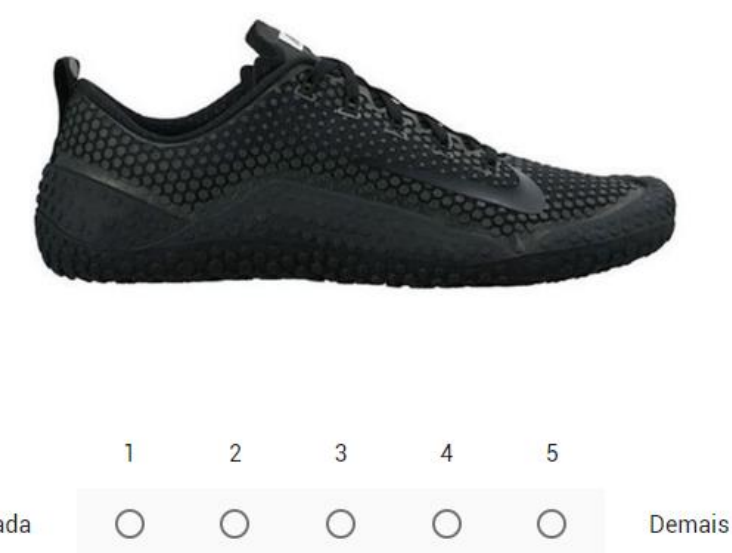

Fonte: Os autores da pesquisa (2018).

O questionário foi posto online e divulgado em grupos com a temática esportiva na rede social Facebook. Ao final, 25 (vinte e cinco) pessoas participaram do levantamento, sendo 18 (dezoito) indivíduos do sexo masculino e 7 (sete) do sexo feminino. Tal divisão é importante pois, conforme citado, foi um objetivo desta pesquisa realizar comparações das preferências desses dois diferentes grupos.

Os dados levantados foram tabulados em Tabelas de Frequências (MARCONI; LAKATOS, 2017), que se constituem nas repetições agrupadas dos valores obtidos através do questionário online, permitindo uma melhor compreensão dos fenômenos.

\section{CONSIDERAÇÕES DE RESULTADOS}

Em termos gerais, os participantes apresentaram uma faixa etária variando de 20 a 60 anos de idade, com uma média de 38 anos. Entre os homens, a média de idade foi de 38,5 anos de idade, enquanto para as mulheres, essa média foi de 36,7 anos. Foi solicitado também que os participantes dissessem sua profissão. Em termos gerais, a opção Professor(a) foi a mais citada 
$17^{\circ}$ ERGODESIGN \& USIHC 2019

PUC-Rio, 11 a 13 de dezembro

Rio de Janeiro, RJ, Brasil $17^{\circ}$ Ergodesign - Congresso Internacional de Ergonomia e Usabilidade de Interfaces Humano Tecnológica: Produto, Informações Ambientes Construídos e Transporte

$17^{\circ}$ USIHC - Congresso Internacional de Ergonomia e Usabilidade de Interfaces Humano Computador

(quatro vezes). Destacaram-se também as ocupações de Estudante (três vezes) e Militar/ Policial Militar (duas vezes cada).

Para a análise dos resultados do levantamento, foram elaboradas três Tabelas de Frequência uma para o público masculino, uma para o público feminino e uma geral. Para Marconi e Lakatos (2017), uma Tabela é uma forma de disposição gráfica, de acordo com determinada ordem de classificação, cujo objetivo é a sintetização dos dados coletados, a fim de torná-los mais compreensivos. Nesse sentido, as Tabelas 1, 2 e 3 abaixo apresentam os valores tabulados para as escolhas de cada participante (linhas) para cada imagem (colunas).

Tabela 1 - Resultados para o público masculino.

\begin{tabular}{c|c|c|c|c|c|c|c|c|c}
\hline Participante & sapato 1 & sapato 2 & sapato 3 & sapato 4 & sapato 5 & sapato 6 & sapato 7 & sapato 8 & sapato 9 \\
\hline P. 01 & 2 & 2 & 1 & 3 & 2 & 3 & 2 & 3 & 2 \\
\hline P. 02 & 1 & 1 & 1 & 1 & 1 & 1 & 1 & 1 & 2 \\
\hline P. 03 & 2 & 2 & 2 & 4 & 3 & 4 & 1 & 4 & 2 \\
\hline P. 04 & 3 & 3 & 2 & 4 & 1 & 1 & 3 & 1 & 3 \\
\hline P. 05 & 2 & 2 & 1 & 3 & 3 & 2 & 5 & 3 & 5 \\
\hline P. 06 & 3 & 3 & 2 & 4 & 2 & 3 & 3 & 2 & 2 \\
\hline P. 07 & 3 & 3 & 3 & 3 & 4 & 3 & 5 & 3 & 5 \\
\hline P. 08 & 5 & 5 & 5 & 4 & 5 & 3 & 5 & 5 & 5 \\
\hline P. 09 & 1 & 3 & 1 & 5 & 4 & 4 & 4 & 4 & 4 \\
\hline P. 10 & 3 & 2 & 2 & 3 & 2 & 3 & 4 & 3 & 3 \\
\hline P. 11 & 1 & 4 & 3 & 5 & 4 & 4 & 3 & 5 & 5 \\
\hline P. 12 & 2 & 3 & 2 & 2 & 3 & 3 & 2 & 3 & 2 \\
\hline P. 13 & 5 & 5 & 4 & 4 & 4 & 5 & 4 & 4 & 3 \\
\hline P. 14 & 1 & 2 & 2 & 3 & 2 & 2 & 4 & 4 & 4 \\
\hline P. 15 & 1 & 2 & 1 & 2 & 2 & 2 & 4 & 4 & 4 \\
\hline P. 16 & 1 & 1 & 1 & 2 & 2 & 3 & 3 & 2 & 5 \\
\hline P. 17 & 1 & 1 & 1 & 1 & 1 & 1 & 5 & 4 & 4 \\
\hline P. 18 & 3 & 3 & 2 & 3 & 2 & 2 & 2 & 2 & 2 \\
\hline Média Total & 2,23 & 2,61 & 1,95 & 3,12 & 2,61 & 2,73 & 3,34 & 3,17 & 3,45 \\
\hline
\end{tabular}

Fonte: Os autores da pesquisa com base nos dados levantados (2018).

Tabela 2 - Resultados para o público feminino.

\begin{tabular}{c|c|c|c|c|c|c|c|c|c}
\hline Participante & sapato 1 & sapato 2 & sapato 3 & sapato 4 & sapato 5 & sapato 6 & sapato 7 & sapato 8 & sapato 9 \\
\hline P. 01 & 1 & 3 & 1 & 3 & 3 & 3 & 5 & 5 & 5 \\
\hline P. 02 & 1 & 1 & 1 & 2 & 3 & 2 & 5 & 3 & 5 \\
\hline P. 03 & 1 & 4 & 4 & 5 & 4 & 4 & 4 & 4 & 5 \\
\hline P. 04 & 3 & 3 & 3 & 4 & 4 & 3 & 4 & 4 & 4 \\
\hline P. 05 & 1 & 2 & 3 & 3 & 3 & 3 & 3 & 3 & 3 \\
\hline P. 06 & 1 & 1 & 1 & 1 & 1 & 4 & 5 & 5 & 5 \\
\hline P. 07 & 1 & 3 & 4 & 4 & 4 & 4 & 3 & 5 & 5 \\
\hline Média Total & 1,29 & 2,43 & 2,43 & 3,15 & 3,15 & 3,29 & 4,15 & 4,15 & 4,58 \\
\hline
\end{tabular}

Fonte: Os autores da pesquisa com base nos dados levantados (2018). 
$17^{\circ}$ ERGODESIGN \& USIHC 2019

PUC-Rio, 11 a 13 de dezembro Rio de Janeiro, RJ, Brasil $17^{\circ}$ Ergodesign - Congresso Internacional de Ergonomia e Usabilidade de Interfaces Humano Tecnológica: Produto, Informações Ambientes Construídos e Transporte

$17^{\circ}$ USIHC - Congresso Internacional de Ergonomia e Usabilidade de Interfaces Humano Computador

Tabela 3 - Resultados gerais

\begin{tabular}{c|c|c|c|c|c|c|c|c|c}
\hline Participante & sapato 1 & sapato 2 & sapato 3 & sapato 4 & sapato 5 & sapato 6 & sapato 7 & sapato 8 & sapato 9 \\
\hline P. 01 & 2 & 2 & 1 & 3 & 2 & 3 & 2 & 3 & 2 \\
\hline P. 02 & 1 & 1 & 1 & 1 & 1 & 1 & 1 & 1 & 2 \\
\hline P. 03 & 2 & 2 & 2 & 4 & 3 & 4 & 1 & 4 & 2 \\
\hline P. 04 & 3 & 3 & 2 & 4 & 1 & 1 & 3 & 1 & 3 \\
\hline P. 05 & 2 & 2 & 1 & 3 & 3 & 2 & 5 & 3 & 5 \\
\hline P. 06 & 3 & 3 & 2 & 4 & 2 & 3 & 3 & 2 & 2 \\
\hline P. 07 & 3 & 3 & 3 & 3 & 4 & 3 & 5 & 3 & 5 \\
\hline P. 08 & 5 & 5 & 5 & 4 & 5 & 3 & 5 & 5 & 5 \\
\hline P. 09 & 1 & 3 & 1 & 5 & 4 & 4 & 4 & 4 & 4 \\
\hline P. 10 & 3 & 2 & 2 & 3 & 2 & 3 & 4 & 3 & 3 \\
\hline P. 11 & 1 & 4 & 3 & 5 & 4 & 4 & 3 & 5 & 5 \\
\hline P. 12 & 2 & 3 & 2 & 2 & 3 & 3 & 2 & 3 & 2 \\
\hline P. 13 & 5 & 5 & 4 & 4 & 4 & 5 & 4 & 4 & 3 \\
\hline P. 14 & 1 & 2 & 2 & 3 & 2 & 2 & 4 & 4 & 4 \\
\hline P. 15 & 1 & 2 & 1 & 2 & 2 & 2 & 4 & 4 & 4 \\
\hline P. 16 & 1 & 1 & 1 & 2 & 2 & 3 & 3 & 2 & 5 \\
\hline P. 17 & 1 & 1 & 1 & 1 & 1 & 1 & 5 & 4 & 4 \\
\hline P. 18 & 3 & 3 & 2 & 3 & 2 & 2 & 2 & 2 & 2 \\
\hline P. 19 & 1 & 3 & 1 & 3 & 3 & 3 & 5 & 5 & 5 \\
\hline P. 20 & 1 & 1 & 1 & 2 & 3 & 2 & 5 & 3 & 5 \\
\hline P. 21 & 1 & 4 & 4 & 5 & 4 & 4 & 4 & 4 & 5 \\
\hline P. 22 & 3 & 3 & 3 & 4 & 4 & 3 & 4 & 4 & 4 \\
\hline P. 23 & 1 & 2 & 3 & 3 & 3 & 3 & 3 & 3 & 3 \\
\hline P. 24 & 1 & 1 & 1 & 1 & 1 & 4 & 5 & 5 & 5 \\
\hline P. 25 & 1 & 3 & 4 & 4 & 4 & 4 & 3 & 5 & 5 \\
\hline Média Total & 1,96 & 2,56 & 2,08 & 3,12 & 2,76 & 2,88 & 3,56 & 3,48 & 3,76 \\
\hline & & & & & & & & 5 \\
\hline
\end{tabular}

Fonte: Os autores da pesquisa com base nos dados levantados (2018).

Conforme indicam as Tabelas, o modelo de tênis de corrida escolhido como favorito nas três situações avaliadas foi o de número nove (tênis de corrida 9), sendo o que apresenta complexidade máxima e contraste alto (coerência baixa) (Figura 2 - Próxima Página). Os tênis de corrida escolhidos como menos preferidos, por sua vez, têm como características em comum o contraste baixo (coerência alta). Na ocasião, enquanto para os homens o menos preferido foi o modelo de número três (complexidade máxima) (Figura 3), o menos preferido para as mulheres e no somatório geral foi o de número um (complexidade mínima) (Figura 4). 
$17^{\circ}$ ERGODESIGN

\section{\& USIHC 2019}

PUC-Rio, 11 a 13 de dezembro

Rio de Janeiro, RJ, Brasil $17^{\circ}$ Ergodesign - Congresso Internacional de Ergonomia e Usabilidade de Interfaces Humano Tecnológica: Produto, Informações Ambientes Construídos e Transporte

$17^{\circ}$ USIHC - Congresso Internacional de Ergonomia e Usabilidade

de Interfaces Humano Computador

Figura 2 - Tênis de corrida selecionado como favorito para ambos os gêneros.

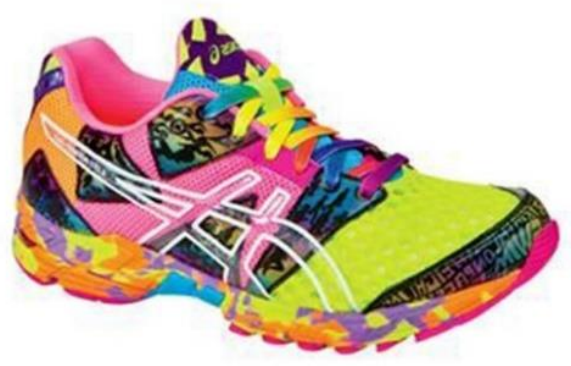

Fonte: Pinterest (2018).

Figura 3 - Tênis de corrida selecionado como menos favorito para o público masculino.

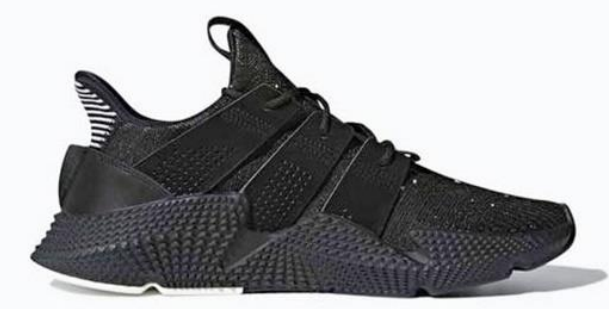

Fonte: Pinterest (2018)

Figura 4 - Tênis de corrida selecionado como menos favorito para o público feminino

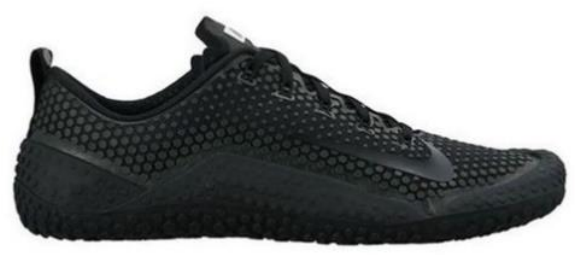

Fonte: Pinterest (2018).

Antes de finalizar essas discussões, cabe destacar que esta abordagem sobre a preferência visual teve enfoque inicial para a avaliação de lugares (COSTA FILHO, 2014), embora venha sendo também ampliada e testada, com resultados consistentes, para artefatos industriais, como, por exemplo, dispositivos de pulso esportivos (SILVA, 2019), smartphones (MOURA, 2018), embalagens de chocolate (FEITOSA, 2017) e relógios de pulsos femininos (SANTOS, 2015). 


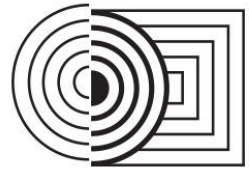

$17^{\circ}$ ERGODESIGN \& USIHC 2019

PUC-Rio, 11 a 13 de dezembro Rio de Janeiro, RJ, Brasil $17^{\circ}$ Ergodesign - Congresso Internacional de Ergonomia e Usabilidade de Interfaces Humano Tecnológica: Produto, Informações Ambientes Construídos e Transporte

$17^{\circ}$ USIHC - Congresso Internacional de Ergonomia e Usabilidade de Interfaces Humano Computador

\section{CONSIDERAÇÕES FINAIS}

De acordo com as escolhas dos participantes desta pesquisa, percebe-se que, de uma forma geral, a preferência por tênis de corrida é elevada pela complexidade máxima e contraste alto (coerência baixa) entre os elementos estéticos do objeto enfocado, ou seja, o tênis de corrida. Essa preferência é reduzida para o contraste médio (coerência média) e decai para o contraste baixo (coerência alta) - independentemente do nível de complexidade presente no objeto. Nesse sentido, conclui-se que a preferência por tênis de corrida não corrobora com os postulados teóricos. Enquanto a pesquisa indica que a preferência pelo produto enfocado é definida pela complexidade máxima e contraste alto (coerência baixa) e que a não preferência é determinada pelo contraste baixo (coerência alta), a teoria afirma que a preferência por entornos estéticos seria estabelecida para a complexidade moderada e contraste baixo (coerência alta), enquanto a não preferência está atrelada a situações opostas a esta. Finalmente, cabe destacar como fator importante, que os achados empíricos aqui apresentados não sejam tomados de forma simplista, pois se tratam de uma compreensão para o tipo de elemento de estímulo apresentado aos participantes abordados como suporte nos questionários online, os grupos selecionados, e o local e a época em que a investigação foi realizada.

\section{REFERÊNCIAS}

BERLYNE, D. E. Ends and meanings of experimental aesthetics. Canadian Journal of Psychology, 26, 1972.

BILSKY, W. A Teoria das Facetas: noções básicas. In Estudos de Psicologia, v.8, n.3, 2003. p. 357-365.

CAVALCANTI, G. Marcas esportivas miram em estilo de vida e performance. Jornal O Globo. Rio de Janeiro, 17 de mar de 2016. Disponível em <https://oglobo.globo.com/economia/marcasesportivas-miram-em-estilo-de-

vida-performance-18894110 >. Acesso em: 30 de novembro de 2018.

COGNATIS. Brasil é mercado promissor quando o assunto é fitness. São Paulo, 3 de janeiro de 2018. Disponível em: < http://www.cognatis.com.br/brasil-e-mercado-promissor-quando-oassunto-e-fitness/>. acesso em: 06 de dezembro de 2017.

COSTA FILHO, L. O enfoque da teoria das facetas na avaliação de lugares. In: V ENEAC ENCONTRO NACIONAL DE ERGONOMIA DO AMBIENTE CONSTRUÍDO E VI SEMINÁRIO NACIONAL DE ACESSIBILIDADE INTEGRAL, 2014. Rio de Janeiro. Anais... Rio de Janeiro, PUC-Rio, LEUI/PUC - Rio. 2014.

FEITOSA, A. S. A influência da cor na preferência por embalagens de chocolate. $84 \mathrm{f}$. Trabalho de Conclusão de Curso (Bacharelado em Design) - Universidade Federal de Pernambuco, Caruaru, 2017.

GFK (Growth from Knowledge). Monitoring health and fitness: 16-country comparison. England: September 27, 2016. Disponível em: <https://www.gfk.com/insights/infographic/monitoringhealth-and-fitness-16-country-comparison/ > acesso em: 06 de dezembro de 2017.

KAPLAN, S. Perception and landscape: conceptions and misconceptions. In NASAR, J. L. (Ed.). Environmental Aesthetics: theory, research, and application. New York: Cambridge University Press, 1988. p. 45-55;

LEAL, G.; MAZZACARO, N.; SZPACENKOPF, M. Como as corridas de rua viraram febre na última década. Jornal $\mathbf{O}$ Globo. Rio de Janeiro, 15 de outubro de 2015. Disponível em $<$ https://oglobo.globo.com/rio/bairros/como-as-corridas-de-rua-viraram-febre-na-ultima-decada17772322 >. Acesso em: 25 de outubro de 2017. 
MARCONI, M.; LAKATOS, E. Técnicas de pesquisa: planejamento e execução de pesquisas, amostragens e técnicas de pesquisas, elaboração, análise e interpretação de dados. 8. Ed. São Paulo: Atlas, 2017.

MOURA, B. S. A sedução de produtos industriais: imagem avaliativa de smartphones. $76 \mathrm{f}$. Trabalho de Conclusão de Curso (Bacharelado em Design) - Universidade Federal de Pernambuco, Caruaru, 2018.

NASAR, J. L. The evaluative image of places. In WALSH, w. b.; CRAIK, k. h; PRINCE, r. h. 2nd ed. (EDs.). Person-Environment Psychology: New directions and perspectives, pp 117-168. New Jersey: Lawrence Erlbaum Associates, 2000.

RUSSEL, J. Affective appraisals of environments. In NASAR, J. L. (Ed.). Environmental Aesthetics: theory, research, and application. New York: Cambridge University Press, 1988. p. 120-129.

SANTOS, L. H. S. A percepção simbólica do relógio de pulso feminino por mulheres da cidade de Caruaru. $72 \mathrm{f}$. Trabalho de Conclusão de Curso (Bacharelado em Design) Universidade Federal de Pernambuco, Caruaru, 2015.

SILVA, R. C. Os efeitos da coerência, complexidade e novidade dos dispositivos de pulso esportivo na qualidade visual percebida. 2019. Dissertação (Mestrado), Programa de PósGraduação em Design, Universidade Federal de Pernambuco, Recife, 2019. 